\title{
Soil protistology rebooted: 30 fundamental questions to start with
}

Stefan Geisen ${ }^{1,33^{*}}$, Edward A. D. Mitchell ${ }^{2,3}$, David M. Wilkinson ${ }^{4,43}$, Sina Adl ${ }^{5}$, Michael Bonkowski ${ }^{6}$, Matthew W. Brown ${ }^{7}$, Anna Maria Fiore-Donno ${ }^{6}$, Thierry J. Heger ${ }^{2}$, Vincent E.J. Jassey ${ }^{8,9}$, Valentyna Krashevska ${ }^{10}$, Daniel J. G. Lahr ${ }^{11}$, Katarzyna Marcisz ${ }^{12,44}$, Matthieu Mulot ${ }^{2}$, Richard Payne ${ }^{13}$, David Singer $^{2}$, O. Roger Anderson ${ }^{14}$, Dan J. Charman ${ }^{15}$, Flemming Ekelund ${ }^{16}$, Bryan S. Griffiths ${ }^{17}$, Regin Rønn ${ }^{16}$, Alexey Smirnov ${ }^{18}$, David Bass ${ }^{19,20}$, Lassaâd Belbahri' ${ }^{2}$, Cédric Berney ${ }^{21,22}$, Quentin Blandenier ${ }^{2}$, Antonis Chatzinotas ${ }^{23,24}$, Marianne Clarholm ${ }^{25}$, Micah Dunthorn ${ }^{26}$, Alan Feest ${ }^{27}$ Leonardo D. Fernández ${ }^{28}$, Wilhelm Foissner ${ }^{29}$, Bertrand Fournier ${ }^{30}$, Eleni Gentekaki ${ }^{31}$, Michal Hajek ${ }^{32}$, Johannes Helder $^{33}$, Alexandre Jousset ${ }^{34}$, Robert Koller ${ }^{35}$, Santosh Kumar ${ }^{36}{ }_{-}^{37}$, Antonietta La Terza ${ }^{37}$, Mariusz Lamentowicz $^{12}$, Yuri Mazei ${ }^{38,39}$, Susana S. Santos ${ }^{40}$, Christophe V.W. Seppey ${ }^{2}$, Frederick W. Spiegel ${ }^{41}$, Julia Walochnik ${ }^{42}$, Anne Winding $^{40}$, Enrique Lara ${ }^{2}$

${ }^{1}$ Department of Terrestrial Ecology, Netherlands Institute of Ecology, 6708 PB Wageningen, The Netherlands

${ }^{2}$ Laboratory of Soil Biodiversity, University of Neuchatel, Rue Emile-Argand 11, Neuchatel 2000, Switzerland

${ }^{3}$ Jardin Botanique de Neuchâtel, Chemin du Perthuis-du-Sault 58, Neuchâtel 2000, Switzerland

${ }^{4}$ Natural Science and Psychology, Liverpool John Moores University, Byrom Street, Liverpool L3 3AF, UK

${ }^{5}$ Department of Soil Sciences, College of Agriculture and Bioresources, University of Saskatchewan, 51 Campus Drive, Saskatoon, Canada 
${ }^{6}$ Department of Terrestrial Ecology, University of Cologne, Zuelpicher Str. 47b, 50674 Cologne, Germany

${ }^{7}$ Department of Biological Sciences, Mississippi State University, Mississippi State, MS, 39762

${ }^{8}$ School of Architecture, Civil and Environmental Engineering (ENAC), Ecole Polytechnique Fédérale de Lausanne EPFL, Ecological Systems Laboratory (ECOS), Station 2, 1015 Lausanne, Switzerland

${ }^{9}$ Swiss Federal Institute for Forest, Snow and Landscape Research (WSL), Site Lausanne, Station 2, 1015 Lausanne, Switzerland

${ }^{10}$ Georg August University Göttingen, J.F. Blumenbach Institute of Zoology and Anthropology, Berliner Str. 28, 37073 Göttingen, Germany

${ }^{11}$ Department of Zoology, Institute of Biosciences, University of São Paulo, Brazil, 05508-090

${ }^{12}$ Laboratory of Wetland Ecology and Monitoring \& Department of Biogeography and Paleoecology, Adam Mickiewicz University, Dzięgielowa 27, 61-680 Poznań, Poland

${ }^{13}$ Environment, University of York, York YO105DD, UK

${ }^{14}$ Biology and Paleoenvironment, Lamont-Doherty Earth Observatory of Columbia University, Palisades, NY, 10964

${ }^{15}$ Department of Geography, College of Life and Environmental Sciences, University of Exeter, Exeter EX4 4RJ, United Kingdom

${ }^{16}$ Department of Biology, University of Copenhagen, Universitetsparken 15, 2100 Copenhagen, Denmark

${ }^{17}$ SRUC, Crop and Soil Systems Research Group, West Mains Road, Edinburgh EH9 3JG, United Kingdom

${ }^{18}$ Department of Invertebrate Zoology, Faculty of Biology, Saint Petersburg State University, Universitetskaya nab. 7/9, St. Petersburg, 199034, Russia 
${ }^{19}$ Department of Life Sciences, The Natural History Museum, London SW7 5BD, United Kingdom

${ }^{20}$ Cefas, Barrack Road, Weymouth, Dorset DT4 8UB, United Kingdom

${ }^{21}$ EPEP-Evolution des Protistes et des Ecosystèmes Pélagiques-team, Sorbonne Universités, UPMC Univ Paris 06, UMR 7144, Station Biologique de Roscoff, Roscoff, France

${ }^{22}$ CNRS, UMR 7144, Station Biologique de Roscoff, Roscoff, France

${ }^{23}$ Helmholtz Centre for Environmental Research - UFZ, Department of Environmental Microbiology, Permoserstr. 15, 04318 Leipzig, Germany

${ }^{24}$ German Centre for Integrative Biodiversity Research (iDiv) Halle-Jena-Leipzig, Deutscher Platz 5e, 04103 Leipzig, Germany

${ }^{25}$ Department of Forest Mycology and Plant Pathology, SLU, Uppsala, Sweden

${ }^{26}$ Department of Ecology, University of Kaiserslautern, 67663 Kaiserslautern, Germany

${ }^{27}$ Faculty of Engineering, University of Bristol, Bristol BS8 1TR, United Kingdom

${ }^{28}$ Centro de Investigación en Recursos Naturales y Sustentabilidad (CIRENYS), Universidad Bernardo O’Higgins, Fábrica 1990, 2o piso, Santiago, Chile

${ }^{29}$ University of Salzburg, Department of Ecology and Evolution, Hellbrunnerstrasse 34, A-5020 Salzburg, Austria

${ }^{30}$ Université Bourgogne Franche-Comté, Laboratoire Chrono-Environnement UMR 6249 CNRS, 16 route de Gray, 25030 Besançon Cedex, France

${ }^{31}$ School of Science, Mae Fah Luang University, Chiang Rai, 57100, Thailand

${ }^{32}$ Department of Botany and Zoology, Masaryk University, Kotlářská 2, 61137 Brno, Czech Republic

${ }^{33}$ Laboratory of Nematology, Wageningen University, Droevendaalsesteeg 1, 6708 PB, Wageningen, The Netherlands

${ }^{34}$ Department of Ecology and Biodiversity, Utrecht University, $3584 \mathrm{CH}$ Utrecht, The Netherlands 
${ }^{35}$ Forschungszentrum Jülich, IBG-2: Plant Sciences, 52425 Jülich, Germany

${ }^{36}$ Department of Biological Sciences, College of Natural Sciences, University of Ulsan, Ulsan 44610, South Korea

${ }^{37}$ School of Bioscience and Veterinary Medicine, University of Camerino, Via Gentile III da Varano, 62032 Camerino (MC), Italy

${ }^{38}$ Department of Hydrobiology, Lomonosov Moscow State University, Leninskiye gory, 1, Moscow 119899, Russia

${ }^{38}$ Department of Zoology and Ecology, Penza State University, Krasnaya str. 40, 440026 Penza, Russia

${ }^{40}$ Department of Environmental Science, Aarhus University, Frederiksborgvej 399, 4000 Roskilde, Denmark

${ }^{41}$ Department of Biological Sciences, University of Arkansas, Fayetteville, AR, 72701

${ }^{42}$ Molecular Parasitology, Institute of Tropical Medicine, Medical University, 1090 Vienna, Austria

${ }^{43}$ School of Life Science, University of Lincoln, UK

${ }^{44}$ Institute of Plant Sciences and Oeschger Centre for Climate Change Research, University of Bern, Altenbergrain 21, CH-3013 Bern, Switzerland

*Corresponding author: Stefan Geisen, Department of Terrestrial Ecology, Netherlands Institute of Ecology, 6708 PB Wageningen, the Netherlands.

Tel: +31 (0)317 4734 00; e-mail: s.geisen@nioo.knaw.nl

Running title: Soil protistology rebooted

Keywords: Soil protists; Protozoa; Microbial interactions; Food web; Biodiversity; Functional diversity 


\section{Abstract}

Protists are the most diverse eukaryotes. These microbes are keystone organisms of soil ecosystems and regulate essential processes of soil fertility such as nutrient cycling and plant growth. Despite this, protists have received little scientific attention, especially compared to bacteria, fungi and nematodes in soil studies. Recent methodological advances, particularly in molecular biology techniques, have made the study of soil protists more accessible, and have created a resurgence of interest in soil protistology. This ongoing revolution now enables comprehensive investigations of the structure and functioning of soil protist communities, paving the way to a new era in soil biology. Instead of providing an exhaustive review, we provide a synthesis of research gaps that should be prioritized in future studies of soil protistology to guide this rapidly developing research area. Based on a synthesis of expert opinion we propose 30 key questions covering a broad range of topics including evolution, phylogenetics, functional ecology, macroecology, paleoecology, and methodologies. These questions highlight a diversity of topics that will establish soil protistology as a hub discipline connecting different fundamental and applied fields such as ecology, biogeography, evolution, plant-microbe interactions, agronomy, and conservation biology. We are convinced that soil protistology has the potential to be one of the most exciting frontiers in biology.

\section{Introduction}

Protists are everywhere, in aquatic and terrestrial ecosystems, free-living, and as symbionts (including parasites) of many organisms including humans. These usually single-celled or colonial microorganisms are by far the most diverse eukaryotes (Adl et al., 2012) and their species-numbers might easily exceed 10 million (Global Soil Biodiversity Atlas; www.globalsoilbiodiversity.org). Since the term 'protista' was introduced (Haeckel, 1866), profound taxonomic re-orderings have taken place. The vast majority of eukaryotic lineages has been shown to be protists, with the exception of the derived monophyletic multicellular lineages: animals, plants, and some fungi (Burki, 2014). 
Electron microscopy and molecular phylogenies have revealed that both algal and protozoan lineages are intermingled throughout the eukaryote phylogenies (Delwiche, 1999; Burki, 2014), and hence it is less confusing to use Haeckel's broader category of 'protist'. Similarly, the classical protozoan morphological categories: flagellates, testate and naked amoebae - but not ciliates - are not monophyletic but distributed across the eukaryotic tree of life (Adl et al., 2012). A snapshot of the immense morphological and phylogenetic diversity of soil protists is visualized in Fig 1 . We therefore recommend to use 'protist' as a term for all single celled phototrophic, mixotrophic and heterotrophic eukaryotes, with the exception of fungi.

The huge diversity of protist species has only recently become evident as many morphospecies recognizable under the microscope were shown to hide many cryptic species (Boenigk et al., 2012a). This 'dark matter of biodiversity' suggests that protist taxon richness has been considerably underestimated. A recent study of environmental eukaryotic diversity based on state-of-the-art highthroughput sequencing (HTS) showed that protists are considerably more diverse than plants and animals in the sunlit zone of oceans (de Vargas et al., 2015). HTS studies of soil protists have shown a wide diversity of non-phagotrophic protists and the diversity of protists in soils is at least as diverse as that in aquatic systems (e.g. (Bates et al., 2013; Geisen et al., 2015c). Nevertheless, soil protists are much less well studied than their aquatic counterparts and this gap is increasing (Fig. 2a).

Soil protists have received relatively little attention mainly due to methodological challenges, especially their isolation from the opaque soil matrix. These, however, do not entirely explain why soil protists are relatively less studied than other soil organisms, especially bacteria, fungi and nematodes (Fig. 2b). The volume of work on microbial bacteria and fungi far outweighs protist studies, possibly because of their direct role as primary decomposers, and they represent monophyletic groups that can more easily be studied with various targeted methodological approaches (Foissner, 1987; Mitchell, 2015). Even soil viruses have been subject to more studies than soil protists, despite being extremely challenging to study (Fierer et al., 2007) and their uncertain functional importance in soils. The under-studied nature of soil protists is exemplified by a 
comparison between research on protists and on soil archaea, a domain erected in 1990 and reported to be functionally important in soil only decade ago (Leininger et al., 2006; Bates et al., 2011). Historically studies mentioning soil protists in the title were eight times more abundant than those including archaea (Fig. 2b, Supplementary Table 2). However, in the last 15 years, this pattern entirely changed; studies on soil protists decreased by $15 \%$ while those on other common soil organisms increased by at least $30 \%$, especially soil archaea which increased by $88 \%$ (Fig. $2 \mathrm{~b}$, Supplementary Table 2).

The relative decline of papers on soil protists strongly contrasts with what we now know about their ubiquity, diversity, and perhaps more importantly, their functional significance. Soil protists can both make an important contribution to primary production (Jassey et al., 2015; Schmidt et al., 2016) and play a key role in the decomposition pathways as consumers of bacteria (Clarholm, 1981; de Ruiter et al., 1995), fungi, other protists, and small invertebrates; they can also act as parasites of plants and animals (Adl and Gupta, 2006; Jassey et al., 2012; Geisen, 2016b). As predators, protists transfer nutrients to higher trophic levels in the soil foodweb (de Ruiter et al., 1995; Crotty et al., 2012). Protist predation also stimulates microbial activity and nutrient cycling via the microbial loop, thus stimulating plant growth (Bonkowski and Clarholm, 2012) and representing an important link between aboveground and belowground components.

The functional significance, abundance, environmental sensitivity, rapid response times and increasing ease of analysis of soil protists also makes them invaluable bioindicators of a variety of aspects of environmental change (Foissner, 1987; Gupta and Yeates, 1997; Payne, 2013). A particular example of this is in paleoecology, where the hard shells of testate amoebae, diatoms and foraminifera are widely used in the reconstruction of past environments and past climate change over a range of timescales (Mitchell et al., 2008; Adl et al., 2011; Charman, 2015).

Most of these applications are, however, based on a few often small-scale studies. Thus significant taxonomic and functional aspects remain largely untouched. Our aim in this report is to pool expert 
knowledge and opinion across the diverse field of soil protistology and soil microbial ecology to identify major knowledge gaps that need to be addressed and their significance for soil processes and ecosystem services.

\section{Materials and Methods}

\subsection{Approach to identify the 30 most relevant questions}

Our aim was to review research gaps both in the field of soil protistology and in general soil biology with a special focus on protists. In line with recent studies (Sutherland et al., 2013; Seddon et al., 2014), we aimed to pool community expertise to identify the most important questions in different broad categories. We modified previously-used methods (Sutherland et al., 2013; Seddon et al., 2014) to obtain a list of most interesting questions through a democratic, transparent, multi-step curation process.

The participants in this process are involved in a wide range of research areas, with self-determined primary research area expressed as being ecology (62\%), palaeoecology (12\%), evolution (9\%), biogeography (6\%), phylogeny (6\%), taxonomy (3\%), parasitology (3\%). Each participant formulated up to 10 questions that they believed were most relevant for their future research. The resulting 368 questions were then compiled via an integrative group effort into consensus questions and placed into six major categories following a discussion by 16 of the participants at the German Society for Protozoology meeting in February 2016. We included very broad, general questions as well as highly specialised topics into similar scaled consensus questions.

The resulting consensus questions were then re-evaluated and groupings adjusted in a vote. These questions (Supplementary Table 1) were sent out to all 47 participants, who individually indicated up to 12 priority questions with at least one being allocated in each of the six following categories: (i) Morphology, Phylogeny, Taxonomy, Evolution and Physiology, (ii) Diversity, Community Composition 
and Biogeography, (iii) Interactions among Protists and other Organisms, (iv) Functions of Protists, (v) Global Change, Bioindicators and Applications, and (vi) Methodology.

All 47 participants were asked to provide their key scientific expertise and literature references for studies that (partly) addressed individual questions. Finally, minor comments raised by individual participants during the vote were integrated to clarify the questions and give consistent formatting without changing the meaning of the questions that had been voted upon.

All individual votes were combined and five questions per category chosen to result in the final list of 30 key questions. When more than one question received the same number of votes (as present in categories 1, 2, and 4), these questions were sent out to all 47 participants for another vote on the selected questions only.

\subsection{Potential limitations}

Biases in broad-scale studies are impossible to avoid (Sutherland et al., 2013). On the other hand, the more interdisciplinary the panel of authors is in terms of cultural and societal background and specific scientific expertise, the more biases are reduced. Researchers working on soil protists are often ecologists, whereas taxonomists, phylogeneticists, and physiologists more often focus on aquatic taxa that are easier to isolate and cultivate. Indeed, participants who indicated ecology as their first expertise dominated our list of participants (62\%). Ecology, however, is a broad field and our division into finer categories such as biogeography, palaeoecology, community structure, and interactions resulted in a broad diversification into different subcategories. Additionally, $21 \%$ of the participants indicated topics such as taxonomy, phylogeny, evolution, and physiology as their main expertise corroborating the wide diversity of research fields among the co-authors.

The majority of participants are PhDs (Professor: 38\%; Graduated scientists: 29\%; Post-doc: $24 \%$ ) with an average number of publications on protists of 43 (minimum $=1$; maximum $=230)$. A high proportion of the participants work on multiple ecosystems (41\%). Many focus on testate amoebae (41\%) although $26 \%$ of them work on multiple morphogroups (ciliates, heterotrophic flagellates, 
amoebae, etc.). A majority (74\%) of participants have a European background, but Asia, North and South America are also well represented, thus reducing potential impacts of geographic origin. Furthermore, most participants have international collaborations that partly compensate for gaps in the geographic distribution of individuals.

Despite these potential limitations, we found few biases in the way participants replied to questions (Supplementary Results 1). Most participants (70\%) selected questions evenly distributed across the six categories, except a small group of people mostly constituted of researchers from the same institute and/or with the same kind of expertise (phylogeny, taxonomy and evolutionary; see Supplementary Results 1 ). This small group allocated $45 \%$ of their votes to the category (ii). Except this small bias, most participants selected questions regardless of their experience, age, geographic background, and most importantly, their expertise and group of interest.

Questions were differently formulated, hence we had to make decisions and remove some nuances as we merged similar questions. This resulted in some discussions about how questions should be best stated and consequently combined and grouped into non-predetermined categories. However, we preferred to receive non-restricted questions to stimulate lateral thinking as previously suggested (Sutherland et al., 2013); due to intensive exchange and to a democratic group effort at all steps of the procedure, we are convinced that we have reached a consensus format. 


\section{Results and Discussion}

\subsection{The 30 most relevant consensus questions}

From the 107 questions in the final vote, $94 \%$ received at least one, $79 \%$ two, $67 \%$ three and $50 \%$ five votes showing that the pre-selected questions had a wide general appeal to the scientific experts involved (Supplementary Table 1). Therefore, all questions seem to be relevant for future studies that focus on soil protists. However, as we aimed at providing a highly specific list of the major research gaps and open challenges in soil protistology, we only provide the top-ranked 30 questions classified in six major categories that most researches voted upon.

\subsection{Categories}

I Morphology, Phylogeny, Taxonomy, Evolution and Physiology

1 How long can protists survive in an encysted form? What are the tolerances of (encysted) protists to stress and what is the importance of cysts for ecosystem resilience?

2 How much morphological and genetic variability exists within soil protists?

3 How do species that occur in both aquatic and soil systems adapt to differing demands?

4 What are the phylogenetic relations of true soil to aquatic protist taxa and how often have soils been colonized by aquatic protists and vice versa?

5 How widespread is sex in soil protists?

Linking the individual topics of this category is one of the major tasks confronting soil protistology. The coupling of morphology and phylogeny is crucial to obtain a stable taxonomic framework for protists. This is, for instance, crucial to answer evolutionary questions on the origin of eukaryotes (López-García and Moreira, 2015). Soil protists may have an important role to play in such research as most taxa likely remain unknown and novel higher-level taxonomic groups are continuously being discovered (Berney et al., 2015; Bass et al., 2016; Singer et al., 2016; Tice et al., 2016). Soil protists 
might fill remaining phylogenetic gaps from better-studied aquatic taxa to improve phylogenetic resolution within and between protist clades, as strict soil protist clades seem to be common (Bass et al., 2016). Sequencing whole genomes will reveal ancient traits of eukaryotes and potential changes in their function during the evolution of eukaryotes. In this respect, soil protists must certainly play a key role for understanding the evolution of the eukaryotic cell and, therefore, of life as a whole.

While the morphological and phylogenetic framework for ciliates is reasonably well established (Lynn, 2008; Foissner, 2016), it remains rudimentary for other morphogroups as well as phylogenetic clades of protists (Kosakyan et al., 2016). The taxonomy of the groups has profoundly benefited from (mainly) 18S rRNA gene-based characterisations that have often led to drastic changes in phylogenetic placements of individual species, genera, families or even orders (Boenigk et al., 2012a; Berney et al., 2015; Bass et al., 2016). This is exemplified by the morphologically and functionally diverse Cercozoa, which was the first protist clade inferred solely based on molecular phylogenetic information, and has become home to ever more morphologically different organisms (Bass et al., 2016). Therefore, the true extent of morphological and genetic variability in different groups of soil protists remains largely unknown and is a key missing gap for future studies (Q2).

A key feature of soil protist species is their capacity for cyst formation as this allows them to resist constantly changing conditions, especially with respect to moisture and temperature. Furthermore, given that protists can excyst after decades, even millennia (Shmakova et al., 2016), cyst formation may protect species from becoming extinct at local or even at the global scales, influence population dynamics and maintain biodiversity (Corliss and Esser, 1974; Jones and Lennon, 2010) The importance of the cyst bank in ecosystem functioning and resilience remains largely unknown and have consequently been identified as a key element for future studies (Q1). More generally, this applies to all specific (physiological) adaptations of soil protists in comparison to their aquatic relatives (Q3, Q4) and to reproduction (Q5).. 
II Diversity, Community Composition and Biogeography

6 What is the real diversity and community structure of soil protists in different systems (e.g. soils, rhizosphere, (plant) endosphere)?

7 How similar are the diversity patterns of soil protists and other soil biota along ecological gradients, and to what extent do different environmental factors shape their respective diversity?

8 What abiotic environmental factors influence the distribution and community composition of protists, and how?

9 How cosmopolitan are protists and how many endemic soil protist species are there?

10 What are dominant groups of soil protists in terms of turnover, abundance and biomass?

We are progressively shedding light into the soil 'black box'; however, knowledge on protists lags behind that of other groups (Fig. 2) (Wilkinson, 2008). Traditional studies have focused exclusively on a few of the 'classic' morphogroups, especially ciliates and testate amoebae, at least partly due to their ease of isolation and feature-rich morphologies (Foissner, 1999). Despite dominating many soil protist communities in terms of numbers and diversity, flagellates and naked amoebae have remained understudied, due to their often smaller sizes, lack of diagnostic features when studied by light microscopy, and the need to establish specialised enrichment cultivation for their isolation from soils (Berthold and Palzenberger, 1995; Foissner, 1999; Smirnov and Brown, 2004; Tikhonenkov et al., 2010). The development of molecular tools such as DNA barcoding and metabarcoding has considerably improved the situation in the last decade (Pawlowski et al., 2012) and allowed a phylogenetically based (morphogroup-independent) and consequently much more detailed analysis of the entirety of soil protist communities. These studies have revealed an enormous diversity of protists inhabiting soils, a phylogenetic diversity that might be similar to that of bacteria (e.g., (Bates et al., 2013; Geisen et al., 2015c; Mahé et al., 2017). Also, groups of protists previously almost unknown from soils have been shown to be common e.g. choanoflagellates, foraminifera, dinoflagellates, parasitic apicomplexans and pathogenic oomycetes (Bates et al., 2013; Geisen et al., 
2015c; Grossmann et al., 2016; Mahé et al., 2017). Therefore, we are only beginning to understand the diversity of soil protists (Q10), which part is active, how this diversity differs in different soil environments (Q6), how protist communities are structured by, e.g., abiotic factors (Q7, Q8) (Geisen et al., 2014a; Lentendu et al., 2014; Geisen et al., 2015c; Dupont et al., 2016).

In addition, the biogeography of (soil) protists has been addressed in some studies, but it is still unclear which and how many groups display a restricted biogeography and what the factors are that shape these distributions $(Q 8, Q 9)$. Although distribution of bacteria may support the hypothesis that "everything is everywhere, but, the environment selects" (Baas-Becking, 1934), its extrapolation to protists has been countered, particularly, by work on ciliates and testate amoebae (Foissner, 2006, 2008; Fernandez et al., 2016). The diversity and biogeographical distribution of protists, is, therefore, one of degree (rather than all cosmopolitan or all limited) and the possibility exists that the investigation of cryptic diversity within morphospecies will allow a finer-scale resolution of these questions.

\section{Interactions among Protists and other Organisms}

11 How do protist taxa affect the composition of the soil microbiome and what other important interactions take place?

12 What are the biotic interactions of soil protists with other taxonomic groups, and how are protists linked within the soil food web?

13 What is the relative contribution of nutrient cycling (i.e. the microbial loop) versus modification of the rhizosphere microbiome in protist-induced stimulation of plant growth?

14 What are the mechanisms by which individual soil protist species affect plant performance, and do those mechanisms differ between plant species?

15 What is the impact of protists on the community functioning of other soil microbes? 
Soil protists are still predominantly considered as being mainly bacterivorous (Bradford, 2016; Geisen, 2016a). Differential feeding by protists stimulated by bacterial volatiles modifies the community composition of bacteria (Bonkowski, 2004; Glücksman et al., 2010; Schulz-Bohm et al., 2017), which results in functional changes in the bacterial community structure (see next section). Many free-living bacteria can, in turn, defend themselves against certain protist predators and even kill them (Greub and Raoult, 2004; Jousset et al., 2006). Several bacteria, viruses, and even other protists can also parasitize protist hosts (Barker and Brown, 1994; Raoult and Boyer, 2010).

The prey spectrum of protists has, however, repeatedly been shown to be much more diverse than bacteria. Indeed, archaea (Ballen-Segura et al., 2017), fungi (Gupta and Germida, 1988; Ekelund, 1998; Adl and Gupta, 2006; Geisen et al., 2016), other protists (Page, 1977; Jassey et al., 2012), and nematodes (Bjørnlund and Rønn, 2008; Geisen et al., 2015b) constitute prey for diverse protist species. Recently, HTS approaches have revealed the ubiquitous presence and dominant roles of protist parasites and pathogens in soils, and they likely represent a key component controlling other soil organisms including larger soil metazoans (animals) and plants (Geisen et al., 2015a; Dupont et al., 2016; Geisen, 2016b). This draws attention to the enormous complexity and importance of protist interactions with other organisms (Bonkowski, 2004).

Due to our limited knowledge of protist diversity and because most studies have used only one or few protists as models, we lack understanding about most aspects of how soil protist communities interact with other organisms. Disentangling the diverse interactions of protists with other soil organisms (Q11, Q12, Q15), the exact mechanisms (Q14) and the resulting importance for functioning $(Q 13, Q 14)$, therefore, are key knowledge gaps necessitating future research.

\section{Functions of Protists}

16 What is the importance of soil protists in biogeochemical cycling?

17 How much functional redundancy is there in the soil protist community?

18 Does increased protist diversity affect ecosystem functioning? 
19 What is the comparative importance of eukaryotic microbes vs. prokaryotes in driving key soil processes?

20 Which individual functions are performed by distinct groups, and what is the entire functional diversity of soil protists?

Many acknowledged functions of soil protists are attributed to interactions with other organisms as outlined above. Especially important is the role of protists in driving the microbial loop, i.e. releasing nutrients (particularly nitrogen) bound in bacterial prey. The microbial loop has been demonstrated both in aquatic (Azam et al., 1983) and soil systems (Clarholm, 1985). This ground-breaking research identified protists as important drivers of the global ecosystem. Subsequent work on the microbial loop demonstrated that differential feeding by protists on bacterial prey is beneficial for plant growth (Bonkowski, 2004; Rosenberg et al., 2009). The main focus in earlier studies was, however, mainly on nitrogen cycling, and the importance of protists for cycling of other elements such as carbon and phosphorus has been relatively neglected, with few exceptions (Cole et al., 1977; Gupta and Germida, 1988; Treonis and Lussenhop, 1997; Frey et al., 2001; Murase et al., 2011; Eisenhauer et al., 2012; Jassey et al., 2015). Protists might even play a role in silica cycling as some use Si as reinforcing elements or in an exoskeleton (Aoki et al., 2007; Creevy et al., 2016). More thorough investigations about the functional roles of additional protist species and communities as a whole will likely reveal insights into the importance of protists in biogeochemical nutrient cycling. This was identified by most participants of this study as the most important question for future research (Q16).

In contrast to free-living protists, plant pathogenic protists, such as oomycetes or plasmodiophorids, have, not surprisingly, attracted considerable attention due to their agro-economic impact (Anderson et al., 2004; Bell et al., 2006; Neuhauser et al., 2014). These were, however, until very recently often considered as 'fungi' (Schardl and Craven, 2003; Gams et al., 2011). Similarly, soil protists with 
immediate relevance for human diseases such as those directly harmful to humans (Schuster, 2002; Siddiqui and Ahmed Khan, 2012; Geisen et al., 2014b) and those that act as "Trojan horses" harbouring human-pathogenic bacteria (Brown and Barker, 1999; Molmeret et al., 2005) have received considerable attention. In turn, the role of protists in plant disease control due to, e.g., increasing bacterial biocontrol agents (Jousset, 2012) or by directly feeding on plant pathogens (Old and Chakraborty, 1986; Geisen et al., 2016) has received comparatively little attention. In line with their importance in nutrient cycling and as biocontrol agents, the role of individual protist species and that of protist diversity for the general functioning of soils and ecosystems (Q17, Q18, Q20), also in comparison to other groups of microbes (Q19), were identified as important questions to be addressed in future studies.

V Global Change, Bioindicators and Applications

21 How do changing climatic patterns affect the diversity of, community structure of and ecosystem services provided by soil protists?

22 Which protist clades can be used as bioindicators to assess soil properties, ecosystem state, and anthropogenic impacts? How could this be implemented?

23 Why are some species more sensitive to environmental change than others, why do some respond faster to environmental factors?

24 How can protists be used for nutrient mobilization and biocontrol in cropping systems?

25 What is the importance of soil protists for biodiversity conservation and ecosystem management and restoration? Should we protect particular species or habitats?

Protist communities are often studied as bioindicators of past and present climatic conditions, land use changes and pollution (Gupta and Yeates, 1997; Mitchell et al., 2008). Abiotic changes affect protists in species-specific ways, thus forming the basis for their use as bioindicators (Fournier et al., 2012). They may, for instance, provide information on soil state in agro-ecosystems (Foissner, 1997, 
1999; Bharti et al., 2015). Testate amoebae and their subfossil remains have been used to evaluate wetland hydrological conditions, applied, for instance, in studies of peatland restoration (Marcisz et al., 2014) and reconstruction of Holocene environmental change (Turner et al., 2014; Lamentowicz et al., 2015; Payne et al., 2015). However, more generally, there has been little progress on evaluating protists as bioindicators even though reliable indicators to assess soil quality continue to be of high relevance (Griffiths et al., 2016) as also revealed here (Q22). Application of protists for stimulating plant performance in terms of nutrition, growth, productivity and disease suppression holds great promise but has received little attention (Q24)

Effects of ongoing global climate change and human impact on the environment are the focus of increasing scientific attention. Global warming has been shown to alter the abundance and community structure of protists (Tsyganov et al., 2011; Jassey et al., 2013) in the limited number of studies that have been done. Predicted changes in precipitation regime will likely affect water availability, which will impact protist communities directly (Clarholm, 1981; Bates et al., 2013; Geisen et al., 2014a). Elevated atmospheric $\mathrm{CO}_{2}$ has also been shown to increase abundance and changes community structure of rhizosphere protists, possibly due to increased plant productivity and enhanced release of root organic exudates (e.g., (Treonis and Lussenhop, 1997; Anderson and Griffin, 2001; Rønn et al., 2002)). Increased air pollution by nitrogen, sulphur, tropospheric ozone and metals are also likely to alter protist abundance and diversity (Meyer et al., 2012; Payne et al., 2012; Payne et al., 2013). Most of these studies focused on testate amoebae, but it is important to study how global environmental changes affect entire protist communities (Q21, Q23, Q25) as these changes are likely to have significant impacts on ecosystem functioning/services and, consequently, on human welfare, and may provide more informative markers of environmental change.

\section{Methodology}

26 What is the most practical taxonomic unit to measure protist diversity? 
27 How can we standardize and calibrate cultivation based and molecular methods to reliably quantify soil protist abundance, diversity and activity?

28 How should sampling be performed to adequately evaluate soil protist diversity?

29 At what scales (temporal, spatial/physical, morphological, phylogenetic) should we study protists to fully understand their diversity and function in soil; which one should be prioritized?

30 How can we infer functional traits of soil protists based on morphology or phylogenetic affiliation, and what taxonomic resolution is needed?

Diverse methods are used to study community structures of soil protists. Even with respect to more classical culturing and morphological observational techniques, the application of methods of nonprotistological disciplines, such as mycology, have the potential of broadening our perspectives on the soil protist community (Spiegel et al., 2004). However, especially recent developments in molecular sequencing technologies, have changed and will continue to change our knowledge about protist diversity and community structure in soils (Bates et al., 2013; Geisen et al., 2015c). However, some issues relating to HTS-based efforts remain as they provide relative abundances of taxa without providing information on absolute abundances. For example PCR-based HTS efforts have been shown to artificially alter the observed community structure of soil protists, a problem which needs to be solved to decipher their real community structure (Geisen et al., 2015a). PCR-free 'omicsapproaches', i.e. metagenomics and metatranscriptomics, might resolve some of these issues (Geisen et al., 2015c; Jacquiod et al., 2016). Indeed, these sequence-based omics approaches and sequenceindependent metaproteomics provide valuable information not only on taxonomic diversity but also on their potential functions (Prosser, 2015). Calibrating, standardizing and adopting communitydefined methodologies to study soil protists will, consequently, be key for cross-study comparisons (Q27) and correct sampling and analyses through different scales need to be defined a priory (Q28, Q29). Furthermore, it is essential to identify the most meaningful taxonomic levels to use in the study of diversity and functioning of soil protists (Q26), but even the definition of a species remains a 
challenge (Boenigk et al., 2012b) and integrating morphology to phylogeny to function remains missing (Q30).

In addition, medical and novel imaging techniques applied to soil are revolutionising in situ work allowing us to study protist species in undisturbed soil and on plant roots. These include applications of NanoSIMS technology to precisely locate isotopic markers and isotopic composition of material in fixed preparations and to study dynamics of nutrient fluxes (Stockdale et al., 2009), which allows tracing nutrient flow from microbial prey to protist predator and further in the food web in high resolution. This will allow detailed investigations how protists selective interact in microsites with their prey, how nutrients become released and where they are translocated. Applications of a variety of Xray based synchrotron spectroscopy and tomography with undisturbed soil is becoming technically feasible and permits the study of dynamics and fluxes at a very fine resolution without interfering with the matrix (Keyes et al., 2013). The ability to use soils with intact fine roots, and examining undisturbed natural soil communities finally provides access to rhizosphere processes. Techniques to measure and analyse chemically soil community molecular interactions and communications are now only a few steps away.

\section{3 (Partial) knowledge gaps and future directions}

In this paper we provide a guide to 30 highly relevant questions for future studies in soil protistology. Research has already been conducted on many of these questions. Literature searches and personal knowledge of the literature allowed us to identify studies that addressed $91 \%$ of the initial and $97 \%$ of the final questions. However, many of these studies focus on organisms other than soil protists (e.g. aquatic protists or non-protist microbes), and may not be directly applicable to the situation with soil protists. The fact that these 30 questions have been identified by our pool of experts strongly implies that previous research has been insufficient to provide conclusive answers. In Supplementary Table 1 we provide an extensive bibliography of previous research relevant to 
addressing these questions. This bibliography will be a valuable literature guide to the current state of the art on soil protistology.

We are beginning to understand many aspects of soil protist biology, as we are identifying the hyperdiverse nature of protist communities, determining their (a)biotic drivers, deciphering interactions with other organisms, and shedding light on their importance in ecosystem dynamics. So far, however, we are only seeing the tip of the iceberg. Addressing many of the 30 questions highlighted here will undoubtedly reveal novel insights, not only into soil protists, but also into other organisms, soils, and fundamental ecological processes. We hope that these questions will be used to catalyse soil protistology and to build research agendas for the future. More specifically, we encourage both protistologists and researchers in closely related fields to consider these questions carefully and to use them to develop new and innovative individual and collaborative projects. With newly available techniques, an increase in knowledge and a growing awareness of the importance of soil protists, we are at the start of a bright future for soil protist research!

\section{Acknowledgements}

We thank Alex K. Tice for providing pictures of Acrasis and Rosculus included in Fig.1. SG thanks Wim van der Putten and his ERC-Adv grant 260-55290 (SPECIALS). We further acknowledge funding by the Swiss Contribution to the enlarged European Union (Project CLIMPEAT: PSPB-013/2010) to ML, KM, MM, VEJJ and EADM, the Russian Scientific Fund (no 14-14-00891) to RJP and YuM, the São Paulo Research Foundation (FAPESP) ( Young Investigator Award no 2013/04585-3) to DJGL, the Swiss National Science Foundation to VEJJ (no 315260_149807), EL, QB and DS (grants no 143960 and 163254), EADM \& TH (no 141188 and 163431), the Chilean Comisión Nacional de Investigación Científica y Tecnológica (CONICYT) (doctoral grants no 21110037 and 78130011), the Universidad de Concepcion (Chile) and the Wildlife Conservation Society (Karukinka-grant no. 2012) to LDFP, and the University of Neuchâtel to LDFP \& CVWS. This is publication XXXX of the NIOO-KNAW.

All authors declare no conflict of interest. 


\section{Author contributions}

SG, EADM and EL designed the study; all authors sent initial questions. SG, TH, VEJJ, DJGL, DS and DW compiled the information and analysed data for Fig. 2. JW, MB, AF, EL, VK, ALT, SK, FS, AS, FE, SG provided photographs that DS, SG, EL and EADM compiled in Fig. 1. SG, EL, EADM, MB, VK, KM, DJGL, MWB, MM, DMW, BSG, SA, RR, AMFD integrated, modified and established the final questions being sent out to all participants. All authors voted on the final list of questions and provided references for separate questions. SG and EL wrote the first draft of the manuscript and all authors contributed substantially to revisions. 


\section{References}

Adl, M.S., Gupta, V.V.S.R., 2006. Protists in soil ecology and forest nutrient cycling. Can. J. For. Res. 36, 1805-1817.

Adl, S., Girard, V., Breton, G., Lak, M., Maharning, A., Mills, A., Perrichot, V., Trionnaire, M., Vullo, R., Néraudeau, D., 2011. Reconstructing the soil food web of a 100 million-year-old forest: The case of the mid-Cretaceous fossils in the amber of Charentes (SW France). Soil Biology and Biochemistry 43, 726-735.

Adl, S.M., Simpson, A.G.B., Lane, C.E., Lukeš, J., Bass, D., Bowser, S.S., Brown, M.W., Burki, F., Dunthorn, M., Hampl, V., Heiss, A., Hoppenrath, M., Lara, E., le Gall, L., Lynn, D.H., McManus, H., Mitchell, E.A.D., Mozley-Stanridge, S.E., Parfrey, L.W., Pawlowski, J., Rueckert, S., Shadwick, L., Schoch, C.L., Smirnov, A., Spiegel, F.W., 2012. The revised classification of eukaryotes. Journal of Eukaryotic Microbiology 59, 429-514.

Anderson, P.K., Cunningham, A.A., Patel, N.G., Morales, F.J., Epstein, P.R., Daszak, P., 2004. Emerging infectious diseases of plants: pathogen pollution, climate change and agrotechnology drivers. Trends in Ecology and Evolution 19, 535-544.

Anderson, R.O., Griffin, K.L., 2001. Abundances of protozoa in soil of laboratory grown wheat plants cultivated under low and high atmospheric $\mathrm{CO} 2$ concentrations. Protistology 2.

Aoki, Y., Hoshino, M., Matsubara, T., 2007. Silica and testate amoebae in a soil under pine-oak forest. Geoderma 142, 29-35.

Azam, F., Fenchel, T., Field, J., Gray, J., Meyer-Reil, L., Thingstad, F., 1983. The ecological role of water-column microbes in the sea. Marine Ecology Progress Series 10, 257-263.

Baas-Becking, L.G.M., 1934. Geobiologie, of inleiding tot de milieukunde. Van Stockum.

Ballen-Segura, M., Felip, M., Catalan, J., 2017. Some Mixotrophic Flagellate Species Selectively Graze on Archaea. Applied and environmental microbiology 83.

Barker, J., Brown, M.R.W., 1994. Trojan Horses of the microbial world: protozoa and the survival of bacterial pathogens in the environment. Microbiology 140, 1253-1259.

Bass, D., Silberman, J.D., Brown, M.W., Tice, A.K., Jousset, A., Geisen, S., Hartikainen, H., 2016.

Coprophilic amoebae and flagellates, including Guttulinopsis, Rosculus and Helkesimastix, characterise a divergent and diverse rhizarian radiation and contribute to a large diversity of faecalassociated protists. Environmental Microbiology 18, 1604-1619.

Bates, S.T., Berg-Lyons, D., Caporaso, J.G., Walters, W.A., Knight, R., Fierer, N., 2011. Examining the global distribution of dominant archaeal populations in soil. The ISME journal 5, 908-917.

Bates, S.T., Clemente, J.C., Flores, G.E., Walters, W.A., Parfrey, L.W., Knight, R., Fierer, N., 2013.

Global biogeography of highly diverse protistan communities in soil. ISME Journal 7, 652-659.

Bell, T., Freckleton, R.P., Lewis, O.T., 2006. Plant pathogens drive density-dependent seedling mortality in a tropical tree. Ecology Letters 9, 569-574.

Berney, C., Geisen, S., Van Wichelen, J., Nitsche, F., Vanormelingen, P., Bonkowski, M., Bass, D., 2015. Expansion of the 'Reticulosphere': diversity of novel branching and network-forming amoebae helps to define Variosea (Amoebozoa). Protist 166, 271-295.

Berthold, A., Palzenberger, M., 1995. Comparison between direct counts of active soil ciliates (Protozoa) and most probable number estimates obtained by Singh's dilution culture method. Biology and Fertility of Soils 19, 348-356.

Bharti, D., Kumar, S., La Terza, A., 2015. Two gonostomatid ciliates from the soil of Lombardia, Italy; including note on the soil mapping project. Journal of Eukaryotic Microbiology 62, 762-772.

Bjørnlund, L., Rønn, R., 2008. 'David and Goliath' of the soil food web - Flagellates that kill nematodes. Soil Biology and Biochemistry 40, 2032-2039.

Boenigk, J., Ereshefsky, M., Hoef-Emden, K., Mallet, J., Bass, D., 2012a. Concepts in protistology: species definitions and boundaries. Eur. J. Protistol. 48, 96-102.

Boenigk, J., Ereshefsky, M., Hoef-Emden, K., Mallet, J., Bass, D., 2012b. Concepts in protistology: species definitions and boundaries. European Journal of Protistology 48, 96-102. 
Bonkowski, M., 2004. Protozoa and plant growth: the microbial loop in soil revisited. New Phytologist 162, 617-631.

Bonkowski, M., Clarholm, M., 2012. Stimulation of plant growth through interactions of bacteria and protozoa: testing the auxiliary microbial loop hypothesis. Acta Protozool. 51, 237-247.

Bradford, M.A., 2016. Re-visioning soil food webs. Soil Biology and Biochemistry 102, 1-3.

Brown, M.R.W., Barker, J., 1999. Unexplored reservoirs of pathogenic bacteria: protozoa and biofilms. Trends in Microbiology 7, 46-50.

Burki, F., 2014. The eukaryotic tree of life from a global phylogenomic perspective. Cold Spring Harbor Perspectives in Biology 6, a016147.

Charman, D.J., 2015. Testate amoebae, In: Shennan, I., Long, A.J. and Horton, B.P. (Eds). (Ed.), Handbook of Sea-Level Research. Wiley, Chichester, pp. 281-294.

Clarholm, M., 1981. Protozoan grazing of bacteria in soil-impact and importance. Microb. Ecol. 7, 343-350.

Clarholm, M., 1985. Interactions of bacteria, protozoa and plants leading to mineralization of soil nitrogen. Soil Biol. Biochem. 17, 181-187.

Cole, C.V., Elliott, E.T., Hunt, H.W., Coleman, D.C., 1977. Trophic interactions in soils as they affect energy and nutrient dynamics. V. Phosphorus transformations. Microbial ecology 4, 381-387.

Corliss, J.O., Esser, S.C., 1974. Comments on the role of the cyst in the life cycle and survival of freeliving protozoa. Transactions of the American Microscopical Society 93, 578-593.

Creevy, A.L., Fisher, J., Puppe, D., Wilkinson, D.M., 2016. Protist diversity on a nature reserve in NW England-With particular reference to their role in soil biogenic silicon pools. Pedobiologia 59, 51-59. Crotty, F., Adl, S., Blackshaw, R., Murray, P., 2012. Protozoan pulses unveil their pivotal position within the soil food web. Microbial ecology 63, 905-918.

de Ruiter, P.C., Neutel, A.M., Moore, J.C., 1995. Energetics, patterns of interaction strengths, and stability in real ecosystems. Science 269, 1257-1260.

de Vargas, C., Audic, S., Henry, N., Decelle, J., Mahé, F., Logares, R., Lara, E., Berney, C., Le Bescot, N., Probert, I., Carmichael, M., Poulain, J., Romac, S., Colin, S., Aury, J.-M., Bittner, L., Chaffron, S., Dunthorn, M., Engelen, S., Flegontova, O., Guidi, L., Horák, A., Jaillon, O., Lima-Mendez, G., Lukeš, J., Malviya, S., Morard, R., Mulot, M., Scalco, E., Siano, R., Vincent, F., Zingone, A., Dimier, C., Picheral, M., Searson, S., Kandels-Lewis, S., Coordinators, T.O., Acinas, S.G., Bork, P., Bowler, C., Gorsky, G., Grimsley, N., Hingamp, P., ludicone, D., Not, F., Ogata, H., Pesant, S., Raes, J., Sieracki, M.E., Speich, S., Stemmann, L., Sunagawa, S., Weissenbach, J., Wincker, P., Karsenti, E., 2015. Eukaryotic plankton diversity in the sunlit ocean. Science 348.

Delwiche, C.F., 1999. Tracing the thread of plastid diversity through the tapestry of life. The American Naturalist 154, S164-S177.

Dupont, A.O., Griffiths, R.I., Bell, T., Bass, D., 2016. Differences in soil micro-eukaryotic communities over soil pH gradients are strongly driven by parasites and saprotrophs. Environ Microbiol 18, 20102024.

Eisenhauer, N., Cesarz, S., Koller, R., Worm, K., Reich, P.B., 2012. Global change belowground: impacts of elevated $\mathrm{CO} 2$, nitrogen, and summer drought on soil food webs and biodiversity. Global Change Biol. 18, 435-447.

Ekelund, F., 1998. Enumeration and abundance of mycophagous protozoa in soil, with special emphasis on heterotrophic flagellates. Soil Biology and Biochemistry 30, 1343-1347.

Fernandez, L.D., Fournier, B., Rivera, R., Lara, E., Mitchell, E.A.D., Hernandez, C.E., 2016. Waterenergy balance, past ecological perturbations and evolutionary constraints shape the latitudinal diversity gradient of soil testate amoebae in south-western South America. Global Ecology and Biogeography 25, 1216-1227.

Fierer, N., Breitbart, M., Nulton, J., Salamon, P., Lozupone, C., Jones, R., Robeson, M., Edwards, R.A., Felts, B., Rayhawk, S., Knight, R., Rohwer, F., Jackson, R.B., 2007. Metagenomic and small-subunit rRNA analyses reveal the genetic diversity of bacteria, archaea, fungi, and viruses in soil. Applied and Environmental Microbiology 73, 7059-7066. 
Foissner, W., 1987. Soil protozoa: fundamental problems, ecological significance, adaptations in ciliates and testaceans, bioindicators, and guide to the literature. Prog. Protistol. 2, 69-212.

Foissner, W., 1997. Protozoa as bioindicators in agroecosystems, with emphasis on farming practices, biocides, and biodiversity. Agr. Ecosyst. Environ. 62, 93-103.

Foissner, W., 1999. Soil protozoa as bioindicators: pros and cons, methods, diversity, representative examples. Agriculture, Ecosystems \& Environment 74, 95-112.

Foissner, W., 2006. Biogeography and dispersal of micro-organisms: a review emphasizing protists. Acta Protozool. 45, 111-136.

Foissner, W., 2008. Protist diversity and distribution: some basic considerations. Biodivers. Conserv. $17,235-242$.

Foissner, W., 2016. Terrestrial and semiterrestrial ciliates (Protozoa, Ciliophora) from Venezuela and Galápagos. Denisia 35, 1-912.

Fournier, B., Malysheva, E., Mazei, Y., Moretti, M., Mitchell, E.A.D., 2012. Toward the use of testate amoeba functional traits as indicator of floodplain restoration success. European Journal of Soil Biology 49, 85-91.

Frey, S.D., Gupta, V.V.S.R., Elliott, E.T., Paustian, K., 2001. Protozoan grazing affects estimates of carbon utilization efficiency of the soil microbial community. Soil Biology and Biochemistry 33, 17591768.

Gams, W., Diederich, P., Poldmaa, K., 2011. Biodiversity of fungi: inventory and monitoring methods, In: Mueller, G.M., Bills, G.F., Foster, M.S. (Ed.), Biodiversity of Fungi: Inventory and Monitoring Methods. Elsevier.

Geisen, S., 2016a. The bacterial-fungal energy channel concept challenged by enormous functional versatility of soil protists. Soil Biology and Biochemistry 102, 22-25.

Geisen, S., 2016b. Thorough high-throughput sequencing analyses unravels huge diversities of soil parasitic protists. Environmental Microbiology 18, 1669-1672.

Geisen, S., Bandow, C., Römbke, J., Bonkowski, M., 2014a. Soil water availability strongly alters the community composition of soil protists. Pedobiologia 57, 205-213.

Geisen, S., Fiore-Donno, A.M., Walochnik, J., Bonkowski, M., 2014b. Acanthamoeba everywhere: high diversity of Acanthamoeba in soils. Parasitology Research 113, 3151-3158.

Geisen, S., Koller, R., Hünninghaus, M., Dumack, K., Urich, T., Bonkowski, M., 2016. The soil food web revisited: Diverse and widespread mycophagous soil protists. Soil Biology and Biochemistry 94, 1018.

Geisen, S., Laros, I., Vizcaíno, A., Bonkowski, M., de Groot, G.A., 2015a. Not all are free-living: highthroughput DNA metabarcoding reveals a diverse community of protists parasitizing soil metazoa.

Mol. Ecol. 24, 4556-4569.

Geisen, S., Rosengarten, J., Koller, R., Mulder, C., Urich, T., Bonkowski, M., 2015b. Pack hunting by a common soil amoeba on nematodes. Environmental Microbiology 17, 4538-4546.

Geisen, S., Tveit, A.T., Clark, I.M., Richter, A., Svenning, M.M., Bonkowski, M., Urich, T., 2015c.

Metatranscriptomic census of active protists in soils. The ISME Journal 9, 2178-2190.

Glücksman, E., Bell, T., Griffiths, R.I., Bass, D., 2010. Closely related protist strains have different grazing impacts on natural bacterial communities. Environ. Microbiol. 12, 3105-3113.

Greub, G., Raoult, D., 2004. Microorganisms resistant to free-living amoebae. Clinical Microbiology Reviews 17, 413-433.

Griffiths, B.S., Römbke, J., Schmelz, R.M., Scheffczyk, A., Faber, J.H., Bloem, J., Pérès, G., Cluzeau, D., Chabbi, A., Suhadolc, M., Sousa, J.P., Martins da Silva, P., Carvalho, F., Mendes, S., Morais, P., Francisco, R., Pereira, C., Bonkowski, M., Geisen, S., Bardgett, R.D., de Vries, F.T., Bolger, T., Dirilgen, T., Schmidt, O., Winding, A., Hendriksen, N.B., Johansen, A., Philippot, L., Plassart, P., Bru, D., Thomson, B., Griffiths, R.I., Bailey, M.J., Keith, A., Rutgers, M., Mulder, C., Hannula, S.E., Creamer, R., Stone, D., 2016. Selecting cost effective and policy-relevant biological indicators for European monitoring of soil biodiversity and ecosystem function. Ecological Indicators 69, 213-223. 
Grossmann, L., Jensen, M., Heider, D., Jost, S., Glucksman, E., Hartikainen, H., Mahamdallie, S.S., Gardner, M., Hoffmann, D., Bass, D., Boenigk, J., 2016. Protistan community analysis: key findings of a large-scale molecular sampling. ISME J 10, 2269-2279.

Gupta, V.V., Yeates, G., 1997. Soil microfauna as bioindicators of soil health. CAB International.

Gupta, V.V.S.R., Germida, J.J., 1988. Distribution of microbial biomass and its activity in different soil aggregate size classes as affected by cultivation. Soil Biology and Biochemistry 20, 777-786.

Haeckel, E., 1866. Generelle Morphologie der Organismen. G. Reimer, Berlin.

Jacquiod, S., Stenbaek, J., Santos, S.S., Winding, A., Sorensen, S.J., Prieme, A., 2016. Metagenomes provide valuable comparative information on soil microeukaryotes. Res Microbiol 167, 436-450. Jassey, V.E.J., Chiapusio, G., Binet, P., Buttler, A., Laggoun-Défarge, F., Delarue, F., Bernard, N., Mitchell, E.A.D., Toussaint, M.-L., Francez, A.-J., Gilbert, D., 2013. Above- and belowground linkages in Sphagnum peatland: climate warming affects plant-microbial interactions. Global Change Biol. 19, 811-823.

Jassey, V.E.J., Shimano, S., Dupuy, C., Toussaint, M.L., Gilbert, D., 2012. Characterizing the feeding habits of the testate amoebae Hyalosphenia papilio and Nebela tincta along a narrow "fen-bog" gradient using digestive vacuole content and $13 \mathrm{C}$ and $15 \mathrm{~N}$ isotopic analyses. Protist 163, 451-464. Jassey, V.E.J., Signarbieux, C., Hättenschwiler, S., Bragazza, L., Buttler, A., Delarue, F., Fournier, B., Gilbert, D., Laggoun-Défarge, F., Lara, E., T. E. Mills, R., Mitchell, E.A.D., Payne, R.J., Robroek, B.J.M., 2015. An unexpected role for mixotrophs in the response of peatland carbon cycling to climate warming. Scientific Reports 5, 16931.

Jones, S.E., Lennon, J.T., 2010. Dormancy contributes to the maintenance of microbial diversity. Proceedings of the National Academy of Sciences 107, 5881-5886.

Jousset, A., 2012. Ecological and evolutive implications of bacterial defences against predators. Environmental Microbiology 14, 1830-1843.

Jousset, A., Lara, E., Wall, L.G., Valverde, C., 2006. Secondary metabolites help biocontrol strain Pseudomonas fluorescens CHAO to escape protozoan grazing. Appl. Environ. Microbiol. 72, 70837090.

Keyes, S.D., Daly, K.R., Gostling, N.J., Jones, D.L., Talboys, P., Pinzer, B.R., Boardman, R., Sinclair, I., Marchant, A., Roose, T., 2013. High resolution synchrotron imaging of wheat root hairs growing in soil and image based modelling of phosphate uptake. New Phytologist 198, 1023-1029.

Kosakyan, A., Gomaa, F., Lara, E., Lahr, D.J.G., 2016. Current and future perspectives on the systematics, taxonomy and nomenclature of testate amoebae. European Journal of Protistology in press.

Lamentowicz, M., Gałka, M., Lamentowicz, Ł., Obremska, M., Kühl, N., Lücke, A., Jassey, V., 2015. Climate change over the last 4000 years in a Baltic bog in northern Poland revealed by a trait-based approach, biotic proxies, and stable isotopes. Palaeogeography Palaeoclimatology Palaeoecology 418, 261-277.

Leininger, S., Urich, T., Schloter, M., Schwark, L., Qi, J., Nicol, G.W., Prosser, J.I., Schuster, S.C., Schleper, C., 2006. Archaea predominate among ammonia-oxidizing prokaryotes in soils. Nature 442, 806-809.

Lentendu, G., Wubet, T., Chatzinotas, A., Wilhelm, C., Buscot, F., Schlegel, M., 2014. Effects of longterm differential fertilization on eukaryotic microbial communities in an arable soil: a multiple barcoding approach. Mol. Ecol. 23, 3341-3355.

López-García, P., Moreira, D., 2015. Open questions on the origin of eukaryotes. Trends in Ecology and Evolution 30, 697-708.

Lynn, D., 2008. The ciliated protozoa: characterization, classification, and guide to the literature, 3rd edition ed. Springer Science \& Business Media, Dordrecht.

Mahé, F., de Vargas, C., Bass, D., Czech, L., Stamatakis, A., Lara, E., Singer, D., Mayor, J., Bunge, J., Sernaker, S., Siemensmeyer, T., Trautmann, I., Romac, S., Berney, C., Kozlov, A.M., Mitchell, E.A.D., Seppey, C.V.W., Egge, E., Wirth, R., Trueba, G., Dunthorn, M., 2017. Parasites dominate hyperdiverse soil protist communities in Neotropical rainforests. Nature Ecology and Evolution 1:0091. 
Marcisz, K., Lamentowicz, Ł., Słowińska, S., Słowiński, M., Muszak, W., Lamentowicz, M., 2014.

Seasonal changes in Sphagnum peatland testate amoeba communities along a hydrological gradient. European Journal of Protistology 50, 445-455.

Meyer, C., D.Gilbert, Gillet, F., Moskura, M., Franchi, M., Bernard, N., 2012. Using "bryophytes and their associated testate amoeba" microsystems as indicators of atmospheric pollution. Ecological Indicators 13, 144-151.

Mitchell, E.A.D., 2015. Pack hunting by minute soil testate amoebae: nematode hell is a naturalist's paradise. Environmental Microbiology 17, 4145-4147.

Mitchell, E.A.D., Charman, D.J., Warner, B.G., 2008. Testate amoebae analysis in ecological and paleoecological studies of wetlands: past, present and future. Biodiversity \& Conservation 17, 21152137.

Molmeret, M., Horn, M., Wagner, M., Santic, M., Kwaik, Y.A., 2005. Amoebae as training grounds for intracellular bacterial pathogens. Applied and Environmental Microbiology 71, 20-28.

Murase, J., Hordijk, K., Tayasu, I., Bodelier, P.L.E., 2011. Strain-specific incorporation of methanotrophic biomass into eukaryotic grazers in a rice field soil revealed by PLFA-SIP. FEMS Microbiol. Ecol. 75, 284-290.

Neuhauser, S., Kirchmair, M., Bulman, S., Bass, D., 2014. Cross-kingdom host shifts of phytomyxid parasites. BMC Evol. Biol. 14, 33.

Old, K.M., Chakraborty, S., 1986. Mycophagous soil amoebae: their biology and significance in the ecology of soil-borne plant pathogens. Progress in protistology 1, 163-194.

Page, F.C., 1977. The genus Thecamoeba (Protozoa, Gymnamoebia) species distinctions, locomotive morphology, and protozoan prey. J. Nat. Hist. 11, 25-63.

Pawlowski, J., Audic, S., Adl, S., Bass, D., Belbahri, L., Berney, C., Bowser, S.S., Cepicka, I., Decelle, J., Dunthorn, M., Fiore-Donno, A.M., Gile, G.H., Holzmann, M., Jahn, R., Jirků, M., Keeling, P.J., Kostka, M., Kudryavtsev, A.A., Lara, E., Lukeš, J., Mann, D.G., Mitchell, E.A.D., Nitsche, F., Romeralo, M., Saunders, G.W., Simpson, A.G.B., Smirnov, A.V., Spouge, J.L., Stern, R.F., Stoeck, T., Zimmermann, J., Schindel, D., de Vargas, C., 2012. CBOL protist working group: barcoding eukaryotic richness beyond the animal, plant, and fungal kingdoms. Plos Biology 10, e1001419.

Payne, R.J., 2013. Seven reasons why protists make useful bioindicators. Acta Protozoologica 52, 105. Payne, R.J., Jassey, V.E., Leith, I.D., Sheppard, L.J., Dise, N.B., Gilbert, D., 2013. Ammonia exposure promotes algal biomass in an ombrotrophic peatland. Soil Biology and Biochemistry 57, 936-938. Payne, R.J., Malysheva, E., Tsyganov, A., Pampura, T., Novenko, E., Volkova, E., Babeshko, K., Mazei, Y., 2015. A multi-proxy record of Holocene environmental change, peatland development and carbon accumulation from Staroselsky Moch peatland, Russia. The Holocene 26, 314-326.

Payne, R.J., Mitchell, E.A., Nguyen-Viet, H., Gilbert, D., 2012. Can pollution bias peatland paleoclimate reconstruction? Quaternary Research 78, 170-173.

Prosser, J.I., 2015. Dispersing misconceptions and identifying opportunities for the use of 'omics' in soil microbial ecology. Nature Reviews Microbiology 13, 439-446.

Raoult, D., Boyer, M., 2010. Amoebae as genitors and reservoirs of giant viruses. Intervirology 53, 321-329.

Rønn, R., Gavito, M., Larsen, J., Jakobsen, I., Frederiksen, H., Christensen, S., 2002. Response of freeliving soil protozoa and microorganisms to elevated atmospheric $\mathrm{CO} 2$ and presence of mycorrhiza. Soil Biology and Biochemistry 34, 923-932.

Rosenberg, K., Bertaux, J., Krome, K., Hartmann, A., Scheu, S., Bonkowski, M., 2009. Soil amoebae rapidly change bacterial community composition in the rhizosphere of Arabidopsis thaliana. ISME Journal 3, 675-684.

Schardl, C.L., Craven, K.D., 2003. Interspecific hybridization in plant-associated fungi and oomycetes: a review. Molecular Ecology 12, 2861-2873.

Schmidt, O., Dyckmans, J., Schrader, S., 2016. Photoautotrophic microorganisms as a carbon source for temperate soil invertebrates. Biology Letters 12. 
Schulz-Bohm, K., Geisen, S., Wubs, E.R.J., Song, C., de Boer, W., Garbeva, P., 2017. The prey's scent Volatile organic compound mediated interactions between soil bacteria and their protist predators. ISME J 11, 817-820.

Schuster, F.L., 2002. Cultivation of pathogenic and opportunistic free-living amebas. Clinical Microbiology Reviews 15, 342-354.

Seddon, A.W.R., Mackay, A.W., Baker, A.G., Birks, H.J.B., Breman, E., Buck, C.E., Ellis, E.C., Froyd, C.A., Gill, J.L., Gillson, L., Johnson, E.A., Jones, V.J., Juggins, S., Macias-Fauria, M., Mills, K., Morris, J.L., Nogués-Bravo, D., Punyasena, S.W., Roland, T.P., Tanentzap, A.J., Willis, K.J., Aberhan, M., van Asperen, E.N., Austin, W.E.N., Battarbee, R.W., Bhagwat, S., Belanger, C.L., Bennett, K.D., Birks, H.H., Bronk Ramsey, C., Brooks, S.J., de Bruyn, M., Butler, P.G., Chambers, F.M., Clarke, S.J., Davies, A.L., Dearing, J.A., Ezard, T.H.G., Feurdean, A., Flower, R.J., Gell, P., Hausmann, S., Hogan, E.J., Hopkins, M.J., Jeffers, E.S., Korhola, A.A., Marchant, R., Kiefer, T., Lamentowicz, M., Larocque-Tobler, I., LópezMerino, L., Liow, L.H., McGowan, S., Miller, J.H., Montoya, E., Morton, O., Nogué, S., Onoufriou, C., Boush, L.P., Rodriguez-Sanchez, F., Rose, N.L., Sayer, C.D., Shaw, H.E., Payne, R., Simpson, G., Sohar, K., Whitehouse, N.J., Williams, J.W., Witkowski, A., 2014. Looking forward through the past: identification of 50 priority research questions in palaeoecology. Journal of Ecology 102, 256-267. Shmakova, L., Bondarenko, N., Smirnov, A., 2016. Viable species of Flamella (Amoebozoa: Variosea) isolated from ancient arctic permafrost sediments. Protist 167, 13-30.

Siddiqui, R., Ahmed Khan, N., 2012. Biology and pathogenesis of Acanthamoeba. Parasites and Vectors 5, 1-13.

Singer, D., Lara, E., Steciow, M.M., Seppey, C.V.W., Paredes, N., Pillonel, A., Oszako, T., Belbahri, L., 2016. High-throughput sequencing reveals diverse oomycete communities in oligotrophic peat bog micro-habitat. Fungal Ecology 23, 42-47.

Smirnov, A.V., Brown, S., 2004. Guide to the methods of study and identification of soil gymnamoebae. Protistology 3, 148-190.

Spiegel, F.W., Stephenson, S.L., Keller, H.W., Moore, D.L., Cavender, J.C., 2004. Biodiversity of fungi: inventory and monitoring methods, In: Mueller, G.M., Foster, M.S., Bills, G.F. (Eds.), Biodiversity of Fungi, Inventory and Monitoring Methods. Elsevier Academic Press, Burlington, MA, pp. 547-576. Stockdale, A., Davison, W., Zhang, H., 2009. Micro-scale biogeochemical heterogeneity in sediments: A review of available technology and observed evidence. Earth-Science Reviews 92, 81-97.

Sutherland, W.J., Freckleton, R.P., Godfray, H.C.J., Beissinger, S.R., Benton, T., Cameron, D.D., Carmel, Y., Coomes, D.A., Coulson, T., Emmerson, M.C., Hails, R.S., Hays, G.C., Hodgson, D.J., Hutchings, M.J., Johnson, D., Jones, J.P.G., Keeling, M.J., Kokko, H., Kunin, W.E., Lambin, X., Lewis, O.T., Malhi, Y., Mieszkowska, N., Milner-Gulland, E.J., Norris, K., Phillimore, A.B., Purves, D.W., Reid, J.M., Reuman, D.C., Thompson, K., Travis, J.M.J., Turnbull, L.A., Wardle, D.A., Wiegand, T., 2013. Identification of 100 fundamental ecological questions. Journal of Ecology 101, 58-67.

Tice, A.K., Shadwick, L.L., Fiore-Donno, A.M., Geisen, S., Kang, S., Schuler, G.A., Spiegel, F.W., Wilkinson, K.A., Bonkowski, M., Dumack, K., Lahr, D.J., Voelcker, E., Clauss, S., Zhang, J., Brown, M.W., 2016. Expansion of the molecular and morphological diversity of Acanthamoebidae (Centramoebida, Amoebozoa) and identification of a novel life cycle type within the group. Biology Direct 11, 69.

Tikhonenkov, D.V., Mazei, Y.A., Embulaeva, E.A., 2010. Effect of ecosystem type on soil heterotrophic flagellate communities under forest-steppe conditions. Protistology 6.

Treonis, A.M., Lussenhop, J.F., 1997. Rapid response of soil protozoa to elevated CO2. Biology and fertility of soils $25,60-62$.

Tsyganov, A.N., Nijs, I., Beyens, L., 2011. Does climate warming stimulate or inhibit soil protist communities? A test on testate amoebae in high-arctic tundra with free-air temperature increase. Protist 162, 237-248.

Turner, T.E., Swindles, G.T., Roucoux, K.H., 2014. Late Holocene ecohydrological and carbon dynamics of a UK raised bog: impact of human activity and climate change. Quaternary Science Reviews 84, 6585. 
Wilkinson, D.M., 2008. Testate amoebae and nutrient cycling: peering into the black box of soil ecology. Trends in Ecology \& Evolution 23, 596-599. 


\section{Figures}

Fig. 1: Common free-living soil protists as visualized by size (lengths), morphology and phylogenetic affiliation. Note, soil protists belong to a wide range of supergroups (in brackets), whereas animals are only placed in the supergroup Opisthokonta. Furthermore, soil protists span a much wider size range as commonly assumed. With the exception of ciliates, morphogroups are not phylogenetically conserved and are placed in different eukaryotic supergroups. Most soil protists can occur in different life forms including active form (amoeba, flagellate, ciliate), but most form cysts, while some can form special reproduction structures (sorocarps and fruiting bodies).

Fig. 2: (a) Overview of studies specifically mentioning protists in the title in 5-year intervals since 1980. Soil studies represent only about a fraction of aquatic studies (separated into freshwater, marine and those that more broadly indicate aquatic) showing a strong increase in protist research in aquatic, but not soil environments; (b) Comparison of soil studies specifically mentioning protists in the title with those on other micro-sized organisms including viruses (blue filled circles), archaea (green open circles), bacteria (red diamonds), fungi (orange crosses) and nematodes (green triangles). See Supplementary Methods for details on the search. 

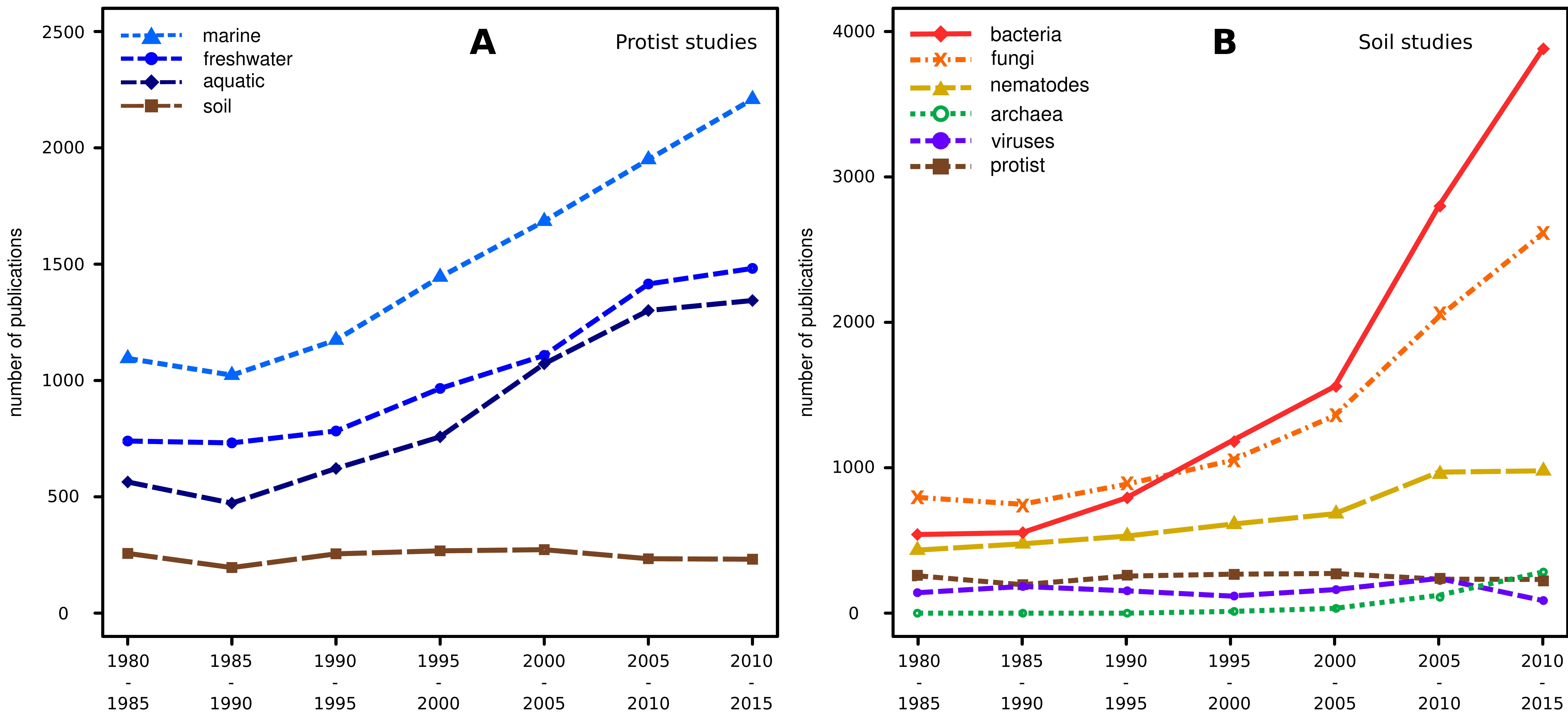